\title{
Abnormal movement related potentials in patients with lesions of basal ganglia and anterior thalamus
}

\author{
A Fève, $\mathbf{N}$ Bathien, $\mathrm{P}$ Rondot
}

Inserm U 97, centre Paul Broca, 2 ter rue France

A Fève

N Bathien

Service de Neurologie, Hôpital Sainte-Anne, 1 rue Cabanis, 75674 Paris, France P Rondot

Correspondence to: A Fève, Service de Paris, France.

Received 27 August 1992 and in revised form 5 March 1993 . 5 March 1993 .
Accepted for publication Accepted for public d'Alésia 75014 Paris, Neurologie, Hôpital Tenon 4 rue de la Chine, 75020

\begin{abstract}
Movement-related cortical potentials (MRCPs) were recorded from scalp electrodes during wrist flexion in $\mathbf{1 5}$ dystonic patients with bilateral (nine) or unilateral (six) circumscribed lesions in the striatum (eight), pallidum (six), or anterior thalamus (one). The results were compared with those of 10 age-matched healthy volunteers. The early (BP) and late (NS') MRCP components were assessed in terms of their gradients and distribution on the scalp in Cz, C3', and C4'. The gradients of both BP and NS' components were significantly flatter in the patients with bilateral lesions than in the control subjects. Also, the BP gradient was maximum at $\mathrm{Cz}$, and the NS' component was contralaterally predominant in the control subjects but not in the patients. In patients with unilateral lesions, the gradients were flatter $(p<$ $0.05)$ during movement of the dystonic wrist than during movement of the normal wrist. This difference was significant for BP and NS', regardless of the location of the electrodes. Also, the normal topographic predominance of $\mathrm{BP}$ at $\mathrm{Cz}$ and of contralateral NS' disappeared. The BP and NS' components of the MRCPs are thought to reflect preparatory activity in the supplementary motor area and the primary motor cortex before movement. Reduced BP and NS' gradients in patients with both bilateral
\end{abstract}

Table 1 Clinical features of the patients

\begin{tabular}{|c|c|c|c|}
\hline Patient & Age at study & Aetiology & $\begin{array}{l}\text { Topography of } \\
\text { lesion by MRI }\end{array}$ \\
\hline \multicolumn{4}{|c|}{ Patients with bilateral lesions: } \\
\hline B1 & $21 / M$ & Encephalitis & Pallidum \\
\hline B2 & $22 / \mathrm{M}$ & Post-hypoxia & Pallidum \\
\hline B3 & $24 / \mathrm{M}$ & Post-hypoxia & Pallidum \\
\hline B4 & $26 / M$ & Post-hypoxia & Pallidum \\
\hline $\begin{array}{l}\text { D5 } \\
\text { B5 }\end{array}$ & $33 / \mathbf{F}$ & Vascular & Putamen and left caudate \\
\hline B6 & $29 / M$ & Birth anoxia & $\begin{array}{l}\text { Putamen } \\
\text { Pan }\end{array}$ \\
\hline B7 & $51 / M$ & Encephalitis & Putamen \\
\hline B8 & $24 / M$ & Birth anoxia & Anterior thalamus \\
\hline \multirow{2}{*}{\multicolumn{4}{|c|}{ Patients with unilateral lesions: }} \\
\hline & & & \\
\hline U10 & $45 / F$ & Cranial trauma & Right putamen \\
\hline U11 & 28/M & Birth anoxia & Right putamen \\
\hline U12 & $42 / \mathrm{M}$ & Cranial trauma & Right putamen \\
\hline $\mathrm{U} 13$ & $27 / F$ & Cranial trauma & Right pallidum \\
\hline U14 & $27 / \mathrm{F}$ & Vascular & Right pallidum \\
\hline U15 & $41 / F$ & Vascular & Right lenticulocaudate \\
\hline
\end{tabular}

$\mathrm{B}=$ bilateral; $\mathrm{U}=$ unilateral and unilateral lesions of the basal ganglia, which project towards the supplementary motor area, are consistent with this hypothesis. The bilateral nature of these reductions suggests that both the ipsilateral and the contralateral motor cortex are involved in the genesis of the MRCPs and that the dystonia in these patients is associated with impaired motor preparation.

\section{$(F$ Neurol Neurosurg Psychiatry 1994;57:100-104)}

The negative slow potentials recorded from the human scalp before and after initiation of voluntary movements are referred to as movement-related cortical potentials (MRCPs). ${ }^{12}$ Shibasaki et $a l^{3}$ have termed the two main premotor components of MRCPs BP and NS'. It has been suggested that BP and NS arise from motor cortical structures, particularly the supplementary motor area and primary motor cortex. ${ }^{45}$ Anatomical studies have shown that the pallidal output is directed from the thalamus to the supplementary motor area and, possibly, to the premotor cortex. ${ }^{6}$ Conversely, the supplementary motor area provides an input into the pallidum via the striatum, thus forming an anatomical loop between motor cortical areas and basal ganglia. ${ }^{7}$ MRCPs might thus reflect the activity of this motor loop. Abnormal MRCPs have effectively been described in Parkinson's disease, ${ }^{8}$ and we found restoration of their amplitude during chronic treatment with levodopa. ${ }^{9}$ Here, we recorded MRCPs in nine dystonic patients with bilateral lesions and six patients with a unilateral lesion of basal ganglia or anterior thalamus.

\section{Subjects and methods}

PATIENTS

Fifteen patients with lesions in the basal ganglia and thalamus were studied after obtaining their informed consent. There were six women and nine men aged between 21 and 51 (mean 30.7 (SD 9.02)) years and they were all right handed. Table 1 shows their main characteristics at the time of the electrophysiological test. All the patients had a dystonia (generalised or hemidystonia) and were free of treatment at the time of examination. 


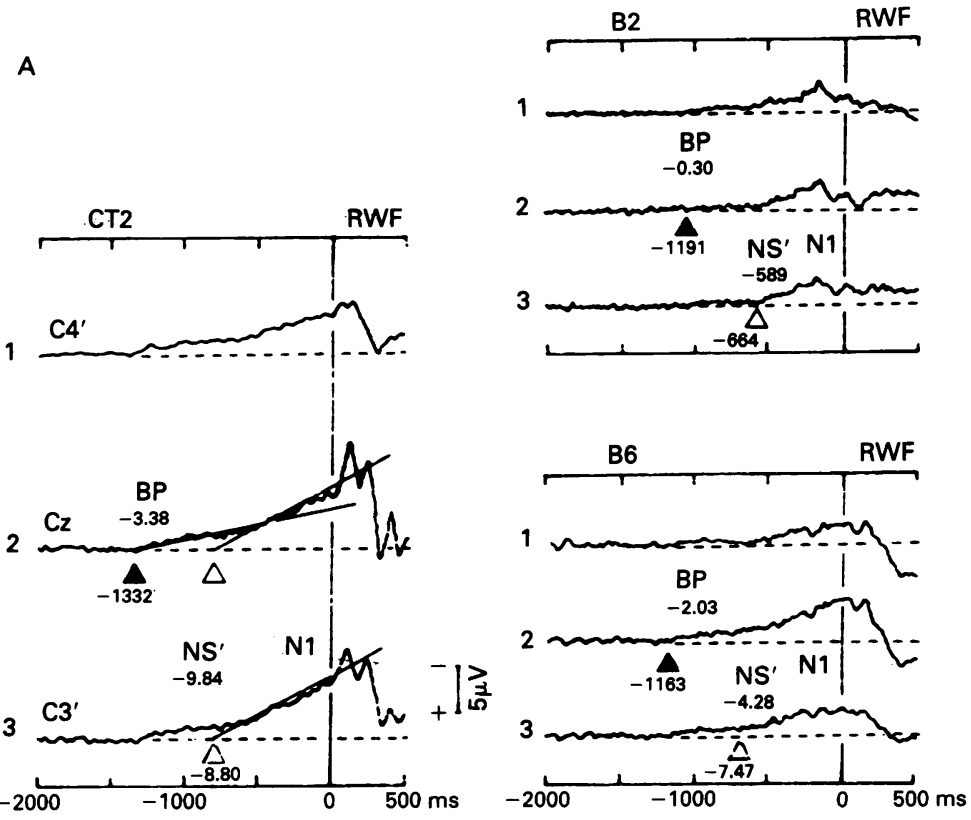

B
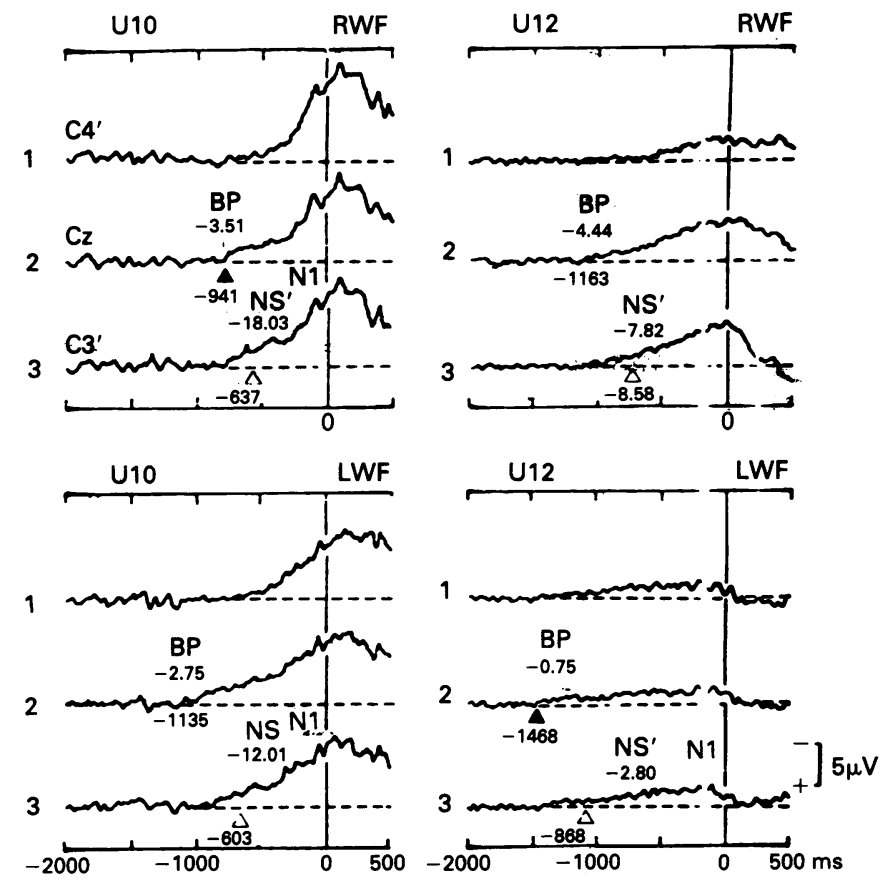

Figure (A) Examples of movement-related cortical potentials (MRCPS) recorded in a healthy subject (CT2) and in patients with bilateral lesions of the pallidum (B2) or putamen (B6). The scalp electrodes were located at C4', $\mathrm{Cz}$, and C3'. Baseline was measured by averaging the first $500 \mathrm{~ms}$ and latencies were measured relative to the baseline with reference to the onset of the EMG recording (point zero). BP is the early component of the shifi and NS' is the late component. The maximum of NS' is N1, before EMG onset. Regression lines were drawn to determine the gradient of the two components.

(B) Examples of MRCPs in patients (U10 and U12) with unilateral lesions of the putamen; on the upper part of the figure wrist flexion of the right (normal) side; on the lower part of the figure left (dystonic) side. Both the BP and NS' gradients were flattened.

Well circumscribed lesions of the basal ganglia were confirmed by MRI. There were nine patients with bilateral lesions and six with unilateral lesions (table 1). The bilateral lesions were pallidal in four patients, striatal in four, and in the anterior thalamus in one. All the unilateral lesions were located in the right hemisphere-four in the striatum and two in the pallidum.
CONTROLS

Ten age-matched right-handed healthy volunteers were chosen from the hospital personnel (six women and four men aged from 23 to 47 (mean 31.3 (SD 7.4)) years. Neurological examination and a CT scan of the head were normal.

\section{RECORDING}

During the recording session the subjects lay comfortably on a bed with their study forearm maintained in a wedge. They were asked to make self-paced, brisk, phasic movements of the wrist, roughly every 5 seconds. The subjects were instructed to fix a point on a screen in front of them, to avoid blinking, and not to count during the interval between movements. Two hundred movements were recorded during each session. The most strongly impaired hand was tested in the patients with bilateral lesions, and both hands were tested in the patients with unilateral lesions. The recording of the healthy volunteers was done during movement of the right wrist.

The surface electromyogram (EMG) was recorded from the flexor carpi ulnaris and amplified within frequencies of $100-3000 \mathrm{~Hz}$. The onset of the EMG burst triggered data collection by a computer assisted system similar to that described by Barrett et al. ${ }^{10}$ EEG potentials preceding self-paced wrist flexions were averaged on line by an evoked potential apparatus (Basis signal averager, OTE) from three scalp electrode positions $(\mathrm{Cz}, \mathrm{C} 3$ ', and C4' $-1 \mathrm{~cm}$ anterior to $\mathrm{C} 3$ and $\mathrm{C} 4$ of the $10 / 20$ system). The filter band pass was 0.03 $\mathrm{Hz}-1.6 \mathrm{kHz}$. Scalp muscle activity and blink artefacts were excluded by a rejection system that automatically discounts potentials greater than $\pm 0 \cdot 1 \mathrm{mV}$. The EEG was averaged from $2 \cdot 5$ seconds before to $2 \cdot 5$ seconds after the upstroke of the EMG.

To measure the amplitude and velocity of the movement, a wedge hinge was placed coaxial to the wrist joint. The hinge contained a potentiometer that allowed the wrist angle to be measured. Angular velocity was measured with an electronic differentiator.

\section{MEASUREMENTS}

The measurements were done by two different investigators who were not informed of the clinical state of the subjects. Baseline was determined by averaging the recording from 2.5 seconds to 2.0 seconds before EMG onset in each channel. The gradients of the two premovement MRCP components (figure) were obtained by fitting a linear regression line between selected points. Onset of BP and peak negativity before EMG onset (N1) were first determined visually. The gradient of the early component was fitted by points on the shift between BP onset and 500 ms later, whereas that of the late component was fitted with points located on the shift between N1 and 500 ms earlier. Onset of NS' was determined on the shift as the intersection of the two regression lines. The figure gives examples. 
STATISTICAL ANALYSIS

The significance of differences between the control subjects and the patients was determined by Student's $t$ test. Differences between recordings over the electrodes of the ipsilateral and contralateral sides were compared by two-way analysis of variance. This was also done for recordings during right or left wrist flexions in the patients with unilateral lesions. Correlations between the movement kinematics and the gradients of the MRCP components were sought by linear regression analysis.

\section{Results}

Patients with bilateral lesions of the basal ganglia The figure (A) shows an example of MRCPs recorded in a control subject (CT2), a patient with bilateral lesions of the pallidum (B2), and a patient with lesions of the putamen (B6). The latencies of the two main premotor components (BP and NS') did not differ between the patients and the control subjects. By contrast, the gradient of BP was flatter on both sides in the patients (mean 1.32 (SD 0.94) $\mu \mathrm{V} / \mathrm{s}$ at $\mathrm{Cz}$ ) than in the control subjects (mean: $-3.3(\mathrm{SD} 1.3) \mu \mathrm{V} / \mathrm{s}$ at $\mathrm{Cz})(\mathrm{p}<0.01)$. The gradient of NS' was also flatter ( -3.4 (SD 1) $\mu \mathrm{V} / \mathrm{s}$ at the contralateral hand motor area) in the patients than in the control subjects $(-8.4$ (SD 1.8) $\mu \mathrm{V} / \mathrm{s}(\mathrm{p}<0.001)$ (table 2).

Changes were also noted in the MRCP topography over the scalp. In the control subjects the BP gradient was significantly greater at $\mathrm{Cz} \quad(\mathrm{p}<0.01)$ and showed a bilateral symetrical distribution at C3' and C4'. NS' was maximum at $\mathrm{C} 3$ ' for a movement of the right wrist. Its mean gradient $(-8.44$ (SD $1 \cdot 81) \mu \mathrm{V} / \mathrm{s}$ ) was significantly steeper $(p<0.001)$ than at C4' $(-5.16$ (SD 1.51) $\mu \mathrm{V} / \mathrm{s}$. In the patients with bilateral lesions, the $\mathrm{BP}$ gradient at $\mathrm{Cz}$ was not significantly different from that at other electrode positions. The NS' gradient at the contralateral hand motor area was not steeper than in the ipsilateral side.

Concerning the movement kinematics (table 2), the velocity of wrist movement in the patients with bilateral lesions was not reduced by more than $74 \%$ (range 90 to 220 degrees/s) relative to the control values. There was no correlation, in either patients or controls, between the velocity and gradients of the MRCPs, either for BP or for NS'.
PATIENTS WITH BILATERAL LESIONS OF THE THALAMUS

Patient B8, who had lesions in the anterior thalamus, showed a pronounced reduction in the gradients of both BP and NS' relative to the control subjects.

\section{PATIENTS WITH UNILATERAL LESION OF THE} BASAL GANGLIA

The figure (B) shows an example of the MRCPs for a movement of the left (dystonic) side in a patient with a limited lesion of the right putamen: scalp recordings of the $B P$ and NS' gradients over the scalp were significantly flatter than during a movement of the unaffected side (BP $p<0.01$, NS' $p<$ $0.05)$. The gradients were also flatter $(\mathrm{p}<$ 0.05 for both BP and NS') relative to those in the control subjects (table 2). During the movement of the dystonic wrist, the gradient was flatter in both ipsilateral and contralateral recordings.

The normal topographic predominance of BP and NS' disappeared during movement of the normal or dystonic wrist. BP was therefore no longer predominant at $\mathrm{Cz}$, and $\mathrm{NS}^{\prime}$ was no longer predominant on the side contralateral to the movement. BP was not maximum at $\mathrm{Cz}$ for either right or left wrist movement. During movement of the right (normal) wrist, BP was predominant at C3' (contralateral normal hemisphere) by comparison with $\mathrm{Cz}$ and C4' (ipsilateral damaged hemisphere) (F 13.47, df 2/10, p < 0.001). There was no effect of electrode position on the BP gradient before left (dystonic) wrist flexion.

\section{NS' DISTRIBUTION}

Comparison of NS' amplitudes in C3', Cz, and C4' by ANOVA showed no significant differences between these electrode locations, whatever the side of the movement.

PARAMETERS OF MOVEMENT

The amplitude of wrist flexions did not differ between the right (dystonic) or a left (normal) sides of movement (table 2 ). The velocity was, however, significantly lower during movement of the affected side (200.8 (SD 29.7) degrees/s) than the normal side (323.3 (SD 38.8) degrees/s) $(\mathrm{p}<0.01)$. No correlation was found between the velocity of movement and the gradient of BP or NS', whatever the side of the movement.

Table 2 Kinematic parameters and MRCPS

\begin{tabular}{|c|c|c|c|c|c|c|}
\hline \multirow[b]{2}{*}{ Patients } & \multicolumn{2}{|l|}{ Kinematic } & \multicolumn{2}{|l|}{$B P$ at $C z$} & \multicolumn{2}{|l|}{$N S^{\prime}$ at $C H M$} \\
\hline & $\begin{array}{l}\text { Angulation } \\
\text { (degrees/s) }\end{array}$ & $\begin{array}{l}\text { Velocity } \\
\text { (degrees/s) }\end{array}$ & $\begin{array}{l}\text { Onset } \\
((-) m s)\end{array}$ & $\begin{array}{l}\text { Slope } \\
((-) \mu V / s)\end{array}$ & $\begin{array}{l}\text { Onset } \\
((-) m s)\end{array}$ & $\begin{array}{l}\text { Slope } \\
((-) \mu V / s)\end{array}$ \\
\hline $\begin{array}{l}\text { Bilateral dystonia (mean }(\mathrm{SD}) \text { ) } \\
\text { Controls (mean }(\mathrm{SD})) \\
\text { Bilateral } v \text { controls }(\mathrm{p} \leqslant) \\
\text { Unilateral dystonia, }\end{array}$ & $\begin{array}{l}85(16) \\
104(11 \cdot 09) \\
0.01 \\
100(6 \cdot 32)\end{array}$ & $\begin{array}{l}165(50) \\
346(33) \\
0 \cdot 001 \\
196(28 \cdot 7)\end{array}$ & $\begin{array}{l}1546(320) \\
1562(198) \\
\text { NS } \\
1309(168.5)\end{array}$ & $\begin{array}{l}1.32(0.94) \\
3.28(1.28) \\
0.01 \\
1.99(1.06)\end{array}$ & $\begin{array}{l}864(194) \\
840(149) \\
\text { NS } \\
826(188 \cdot 7)\end{array}$ & $\begin{array}{l}3.41(1.00) \\
8.41(1.81) \\
0.001 \\
6.32(3.87)\end{array}$ \\
\hline $\begin{array}{l}\text { dystonic side (mean (SD)) } \\
\text { Unilateral dystonia, } \\
\text { normal side (mean (SD)) }\end{array}$ & $105(5 \cdot 47)$ & $355(17 \cdot 6)$ & $1150(202 \cdot 7)$ & $4 \cdot 11(1 \cdot 16)$ & $740 \cdot 6(98 \cdot 8)$ & $10 \cdot 87(4 \cdot 18)$ \\
\hline Normal $v$ dystonic $(\mathrm{p} \leqslant)$ & NS & 0.001 & NS & 0.01 & NS & 0.05 \\
\hline
\end{tabular}

$\mathrm{CHM}=$ contralateral hand motor area . 


\section{Discussion}

Relative to the healthy control values, both the BP and NS' gradients were flatter on both sides in the patients with bilateral lesions of the basal ganglia, and before movement of the impaired side in patients with unilateral lesions. All these patients had circumscribed ischaemic lesions of the pallidum, putamen, caudate nucleus, or anterior thalamus. These features are consistent with the involvement of basal ganglia and anterior thalamus in principal neuronal motor circuits, ${ }^{11}$ the "complex loop" (prefrontal cortex, caudate nucleus, pallidum and substantia nigra, ventral anterior thalamus, prefrontal cortex), and the "motor" loop (premotor and sensorymotor cortex, putamen, pallidum, and substantia nigra, ventrolateral thalamus, premotor and sensory-cortex). As MRCPs are thought to originate from both the primary motor cortex and the supplementary motor area ${ }^{1213}$ their decrease could reflect lower activity of motor cortical structures due to lesions in the basal ganglia. Failure of cortical activation of patients with Parkinson's disease and those with lesions of subcortical structures, particularly of the basal ganglia, has already been reported. ${ }^{14-16}$ These reports are in agreement with the decrease in MRCPs found here.

As well as the flattening of the gradients relative to those in the healthy control subjects, a change of the topographic distribution and a bilateral decrease in the MRCPs was noted during movement of the impaired side in the patients with unilateral lesions. As surface recording of the MRCPs probably reflects activities of both the right and the left motor cortex before voluntary movement, ${ }^{17}$ a large unilateral decrease in the activity of one hemisphere could produce a decrease in both right and left MRCPs recorded on the scalp. The activity of motor cortex structures could also be bilaterally reduced, however, in patients with unilateral lesions of the basal ganglia. Indeed, both bilateral supplementary motor areas are activated before unilateral, spontaneous, purposeful movement, as shown by subdural MRCP recordings ${ }^{1213}$ and cerebral blood flow. ${ }^{18}$

As MRCPs probably reflect motor preparation before ballistic self-paced movements, ${ }^{19}$ our results could be due to an impairment of motor preparation after lesions of the basal ganglia. Various motor disorders have been described after such lesions. ${ }^{20}$ Parkinson's disease is another condition in which there are elective lesions of these structures. Although an earlier study of MRCPs in Parkinson's disease gave conflicting results, Dick et $a l^{1821}$ showed that the earlier component of MRCPs was clearly reduced in patients with Parkinson's disease. In the early stages of Parkinson's disease, changes in MRCPs were limited to the BP component but in later stages the two premotor components were altered. ${ }^{9}$ Furthermore, there was a relation between amplitude of MRCPs and motor Parkinsonian scores. ${ }^{22}$ The patients we studied are dystonic and, as bradykinesia is seen in Parkinson's disease, the pathophysiology of dystonic movement remains unclear. Although the movement of our patients were slower than in control subjects, the velocity was never less than $26 \%$ of normal and this was not sufficient to affect the MRCP gradients, which have been noted to be affected for a reduction of more than $90 \%$ of the velocity of movement. ${ }^{21}$ Also, there was no positive linear correlation between velocity and MRCP gradients. This suggests that the impaired motor control in dystonic subjects does not affect the velocity directly, but rather other parameters of motor programming, as has been suggested by peripheral recordings. ${ }^{23}$ One of the involved parameters could be the increasing amplitude of muscular potentials at the onset of the muscular burst. Thus Hallett and Khoshbin ${ }^{24}$ hypothesised that the basal ganglia are concerned with the grading of movement amplitudes by inappropriate energising of muscles.

Our results suggest that dystonic movements may be associated with a decrease in motor cortex activity due to a disruption of the striato-pallido-thalamo-cortical loop by a vascular lesion. Although MRCP flattening after lesions of the basal ganglia raises the problem of cortical or subcortical origin of its components, this study provides new insights concerning the relation between lesions of the basal ganglia and genesis of dystonia.

We thank Miss Clara Bazzinotti for typing and Mr David Young for reading the text.

1 Kornhuber HH, Deecke L. Hirnpotentialanderungen bei Willkurbewegungen und passiven Bewegungen des Menschen: Bereitschatspotential und reafferente potentiale. Pfügers Arch 1965;284:1-17.

2 Vaughan Jr HG, Costa LD, Ritter W. Topography of the human motor potential. Electroencephalogr Clin Neurophysiol 1968;25:1-10.

3 Shibasaki H, Barrett G, Halliday E, Halliday AM. Components of the movement-related cortical potentials and their scalp topography. Electroencephalogr Clin Neurophysiol 1980;49:213-26.

4 Deecke L, Kornhuber HH. An electrical sign of participation of the mesial "supplementary" motor cortex in tion of the mesial "supplementary" motor cortex in human 6 .

5 Deecke $\mathrm{L}$. Bereitschaftspotential as an indicator of movement preparation in supplementary motor area and motor cortex. In: Bock G, O'Connor M, Marsh J, eds. Motor areas of the cerebral cortex. Chichester: John W
1986:231-50. (Ciba Foundation Symposium 132.)

6 Schell GR, Strick PL. The origin of thalamus inputs to the arcuate premotor and supplementary motor areas. f Neurosci 1984;4:539-60.

7 Künzle H. An autoradiographic analysis of the efferent connections for premotor and adjacent prefrontal regions (areas 6 and 9) in Macaca fascicularis. Brain Behav Evol 1978;15:185-234.

8 Dick JPR, Rothwell JC, Day BL, et al. The Bereitschaftspotential is abnormal in Parkinson's disBereitschaftspotential is abn

9 Fève AP, Bathien N, Rondot P. Chronic administration of $L$ dopa affects the movement-related cortical potenof $L$ dopa affects the movement-related cortical potentials in patients with Park

10 Barret G, Shibasaki H, Neshige R. A computer assisted method for averaging movement-related cortical potenmethod for averaging movement-related cortical poten-

11 Delong MR, Georgopoulos AP, Crutcher MD. Corticobasal ganglia relations and coding of motor performance. Exp Brain Res 1983;7:158-68.

12 Neshige $R$, Lüders $H$, Shibasaki $H$. Recording of movement-related potentials from scalps and cortex in man. Brain 1988;111:719-36. 
13 Ikeda A, Lüders H, Burgess RC, Shibasaki H. Movementrelated potentials recorded from supplementary motor related potentials recorded from supplementary motor area and primary motor area. Role of supplementary motor area

14 Leenders KL, Palmer AJ, Quinn N, et al. Decrease metabolism in patients with Parkinson's disease measured with PET. If Neurol Neurosurg Psychiatry 1986;49. 853-60.

15 Wolfson $L$, Leenders $K L$, Brown $L L$, Jones $T$. Alterations of regional cerebral blood flow and oxygen metabolism in Parkinson's disease. Neurology 1985;35: 1399-405.

16 Deecke L, Englitz HG, Kornhuber HH, Schmmitt G. Cerebral potentials preceding voluntary movement in patients with bilateral or unilateral Parkinson's akinesia. In: Desmedt JE, ed. Attention voluntary contraction and event-related cerebral potentials: Progress in Clinical Nevent-related cerebral potentials:

17 Arezzo J, Vaughan HG. Intra cortical sources and surface topography of the motor potential and somatosensory topography of the motor potential and somatosensory
evoked potentials in the Monkey. In Kornhuber HH,
Deecke L, eds.: Progress in brain research vol 54; motivaDeecke $\mathrm{L}$, eds.: Progress in brain research vol 54 ; motiva-
tion, motor and sensory processes of the brain: Electrical potentials, behaviour and clinical use. Amsterdam: Elsevier Science Publisher, 77-88.

18 Roland PE, Larsen B, Lassen NA, Shinoj E Supplementary motor area and other cortical areas Supplementary motor area and other cortical areas
in organization of voluntary movements in man. in organization of voluntary

19 Libet B, Gleason CA, Wright EW, Pearl DK. Time of conscious intention to act in relation to onset of cerebral activity (readiness-potential). Brain 1983;106:623-42.

20 Fève AP, Fénelon G, Wallays C, Rémy P, Guillard A. Axial motor disturbances after hypoxic lesions of the globus pallidus. Mov Disord 1993;8:321-6.

21 Dick JPR, Cantello R, Buruma O, et al. The Bereitschaftspotential, L-Dopa and Parkinson's disease. Electroencephalogr Clin Neurophysiol 1987;66:263-74.

22 Fève AP, Bathien N, Rondot $\mathrm{P}$. Evolution des potentials corticaux liés au mouvement chez les patients parkinsoniens, avant et après traitment par la levodopa. Rev EEG Neurophysiol Clin 1991;21:105-19.

23 Van der Kamp W, Berardelli A, Rothwell JC, et al. Rapid elbow movements in patients with torsion dystonia. I Neurol Neurosurg Psychiatry 1989;52:1043-9.

24 Hallett M, Khoshbin S. A physiological mechanism of bradykinesia. Brain 1980;103:301-14. 